\title{
A Redundant Recurrent Cerebellar Model Articulation Control System for Industrial Applications
}

\author{
Van-Phuong Ta \\ Department of Automatic Control \\ HCMC University of Technology And Education \\ Ho Chi Minh City, Vietnam \\ phuongtv@hcmute.edu.vn
}

\author{
Xuan-Kien Dang \\ Graduate Institute \\ HCMC University of Transport \\ Ho Chi Minh City, Vietnam \\ dangxuankien@hcmutrans.edu.vn
}

\begin{abstract}
Because of increasing reliability requirements of the applications in industrial areas, the control systems must guarantee the stability and robustness during operation and continuously maintain control and supervisory process. In order to meet the above requirements, this study proposes a redundant recurrent cerebellar model articulation control system (RRCMACS) for controlling industrial applications, in particular the water level and the pressure in a tank. Therein, the stability and the robustness of the applications are guaranteed by the recurrent cerebellar model articulation controller (RCMAC) and the redundant solution maintains continuously control and supervisory process. To adapt industrial applications, a Programmable Logic Controller (PLC) was used to build the control system and industrial networks were used to transfer data between the control system and field devices.
\end{abstract}

Keywords-recurrent cerebellar model articulation controller (RCMAC); redundancy system; industrial communication network; uncertainties; non-linear system

\section{INTRODUCTION}

Stability control of level and pressure in a tank are crucial tasks in industrial applications [1-3]. Because of the effects of the uncertainties due to dynamic perturbations and signal noises, the dynamic model of these systems cannot be completely obtained [4-7]. Consequently, model-based controllers cannot achieve the desired performances [8-10]. To overcome these disadvantages, advanced controllers such as fuzzy logic controller (FLC) [11, 12], sliding mode control (SMC) $[13,14]$, neural networks (NN) $[15,16]$, and wavelet neural network (WNN) [17-21] have been developed and have achieved impressive results in dealing with uncertain systems. In the above-mentioned advanced controllers, however, there are still difficulties in designing the control systems. For the FLC, the selection of fuzzy sets and rules is dependent on the prior experience of the system. In the SMC, selection boundary of uncertainties or disturbance is a trade-off between stability and chattering phenomena. For the $\mathrm{NN}$ and $\mathrm{WNN}$, the selection of the number of neurons and hidden layers to achieve good performance and learning requirements is extremely difficult in practical applications.
Cerebellar Model Articulation Controller (CMAC) is a learning structure that mimics human brain [22]. The CMAC has been developed and adopted for uncertain non-linear Multiple-Input and Multiple-Output (MIMO) systems due to properties such as fast learning, good generation capability, and simple computation. The augmented effectiveness in applications of the CMACs when compared to NNs has been proved [23-26]. In recent researches, the wavelet function and recurrent technique were incorporated into the CMAC to improve the learning capability and dynamic response of the traditional CMAC [27-30]. The above adaptive, intelligent controllers can deal with the uncertainties and non-linear characteristic of the systems to achieve the desired performance. The industrial applications of these controllers, however, have been limited. In addition, the redundant solution has not been mentioned to continuously maintain control and supervisory process. This paper proposes an RRCMACS to achieve the desired responses and continuously maintain control and supervisory process. The recurrent cerebellar model articulation (RCMAC) is designed to keep the stability and the robustness, and the redundant solution aims to maintain the continuous working of the control system. To meet the requirements of the industrial area, the PLC was used to build the control system and industrial networks were used to transfer data between the control system and field devices.

\section{SYSTEM DESCRIPTION}

\section{A. Structure and Operation of the Redundant System}

The structure of the redundant system and a photograph of its implementation are shown in Figures 1 and 2 respectively. The redundant system includes a primary station (PS) and a standby station (SS), which continuously maintain the control and supervisory process of the control system. In particular, the system used DeviceNet Network to control and monitor the pressure and water level in a tank. The ControlNet network was used to transfer diagnostic information between the PS and SS to take over control as satisfying prescribed conditions. At the beginning of the process, the station that started earlier takes the role of the PS and takes control over the system, while the other station works as the SS. During operation, if the PS 
faults, the SS will take over to maintain control and the supervisory process of the system. In addition, the RCMAC was utilized to guarantee the stability and robustness of the system during operation. The RCMAC was downloaded to both stations, thus the effectiveness of the control and supervisory process was the same with in both stations.

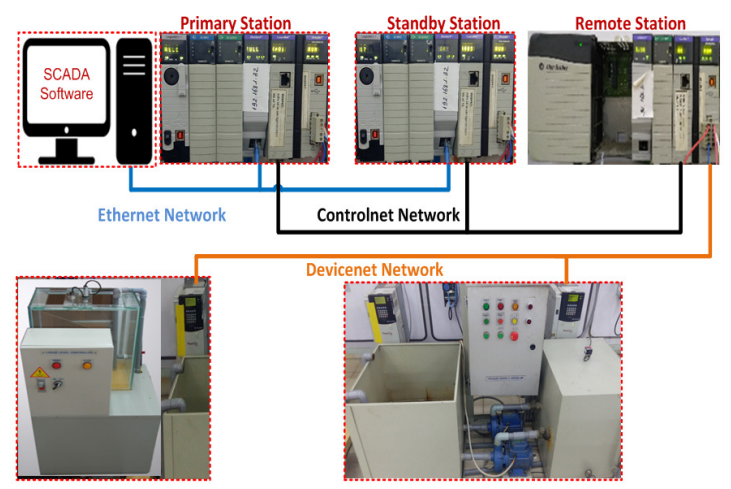

Fig. 1. Structure of the redundant system

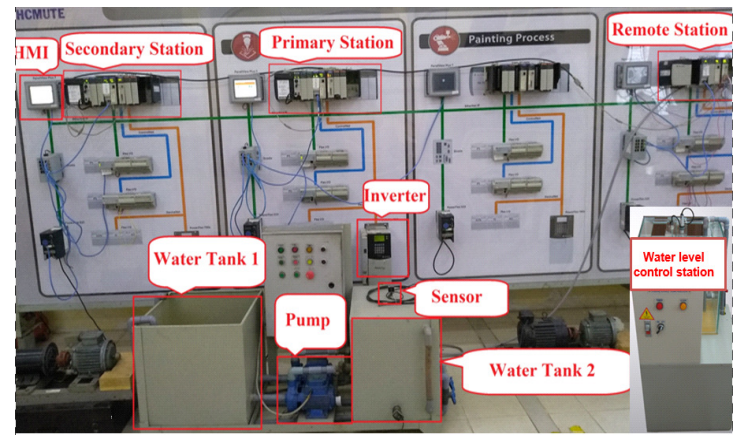

Fig. 2. Experiments of the RCMACS

\section{B. Control Takeover}

During operation, the controllers monitor the working conditions of each other. A "Heartbeat" parameter is used to measure the strength of the controllers. When this parameter falls down under a prescribed threshold, it means the controllers are having faults while handling the system. In particular, assuming that the PS owns the control system at the beginning of the process, it monitors the connections of the devices in the system during operation. If there are fault connections suddenly inhibiting these devices, the SS can communicate with them in order to control the system. In addition, the SS always monitors the status of the PS. Whenever the PS has problems with connections, the SS immediately takes over control of the system. Figure 3 describes the process of control takeover between the PS and SS. The flowchart of control takeover is shown in Figure 4.

\section{RCMAC}

Along with continuously maintaining the control and supervisory process of the system, stability and robustness of the system are also a crucial task in the industrial applications. This duty is handled by the RCMAC. The dynamic model of practical applications is extremely difficult to define.

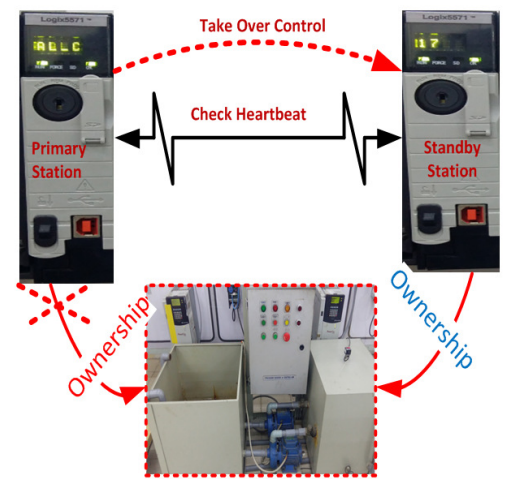

Fig. 3. Take over control between two CPU

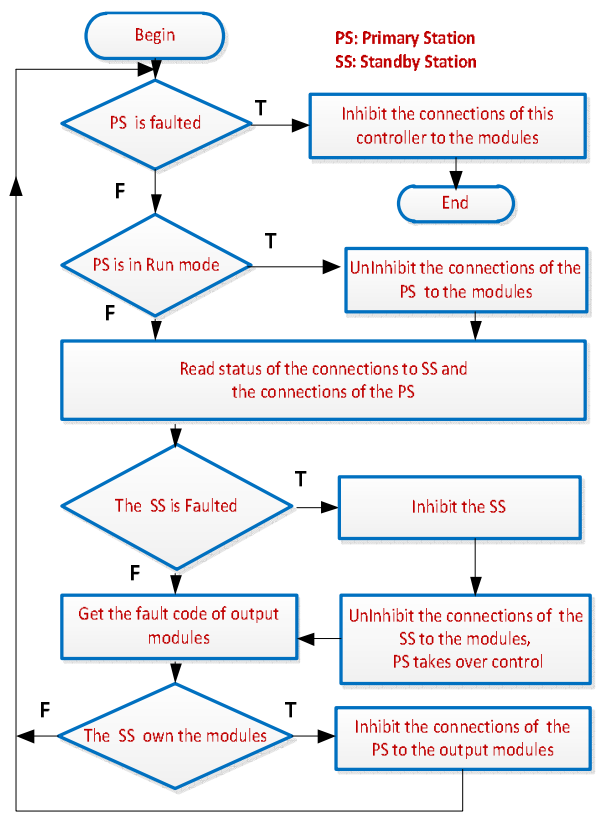

Fig. 4. The flowchart of control takeover

In this study, the dynamic equation of the pressure control system and the water level control system are identified by the Matlab tool. The linearized dynamic models, including uncertainties of the system are given by (1) and (2), respectively:

$$
\begin{aligned}
& \ddot{y}(t)+0.045 \dot{y}(t)+0.0017 y(t)+U D(t)=0.0045 u(t)(1) \\
& \ddot{y}(t)+0.00035 \dot{y}(t)+0.001 y(t)+U D(t)=0.165 u(t)(2)
\end{aligned}
$$

where $\mathrm{u}(\mathrm{t})$ and $\mathrm{y}(\mathrm{t})$ are control signal and the pressure in the Tank or water level. UD(t) is the lumped uncertainties and linearization error. Equations (1) and (2) can be rewritten in state equation form as:

$$
\left\{\begin{array}{l}
\ddot{\mathrm{x}}=\mathrm{F}_{0}(\underline{\mathrm{x}})+\mathrm{G}_{0}(\underline{\mathrm{x}}) \mathrm{u}+\mathrm{UD}(\underline{\mathrm{x}}) \\
\mathrm{y}=\mathrm{x} ; \underline{\mathbf{x}}=\left[\mathrm{x}^{\mathrm{T}} \dot{\mathrm{x}}^{\mathrm{T}}\right]^{\mathrm{T}}
\end{array}\right.
$$


In the case of $F_{0}(\underline{x}), G_{0}(\underline{x})$, and well-known uncertainties $\mathbf{U D}(\underline{\mathrm{x}})$, an ideal controller can be designed as [27, 30]:

$$
\mathrm{u}_{\mathrm{i}}=\mathrm{G}_{0}^{-1}(\underline{\mathrm{x}})\left[\ddot{\mathrm{y}}_{\mathrm{d}}-\mathrm{F}_{0}(\underline{\mathrm{x}})-\mathrm{UD}(\underline{\mathrm{x}})+\mathrm{K}_{1} \dot{\mathrm{e}}+\mathrm{K}_{2} \mathrm{e}\right]
$$

where $\mathrm{K}_{1}, \mathrm{~K}_{2}$ are selected to the error dynamic equation $\ddot{\mathrm{e}}+\mathrm{K}_{1} \dot{\mathrm{e}}+\mathrm{K}_{2} \mathrm{e}=0$ satisfying the Hurwitz criterion.

However, the uncertainties, $\operatorname{UD}(\underline{x})$ cannot be defined in the practical systems, thus the ideal controller $u_{i}$ does not guarantee the desired performance. To deal with the uncertainties, a proposed control system is depicted in Figure 3. In this system, the recurrent cerebellar model articulation controller $\mathrm{u}_{\mathrm{RCMAC}}$ is combined with a compensator controller $\mathrm{u}_{\mathrm{CC}}$ to achieve stability and robustness. Therein, the $\mathrm{u}_{\mathrm{RCMAC}}$ is developed to mimic the ideal controller and by its learning capability to achieve stability while the compensator controller is designed to attenuate efficiently the effects of uncertainties to obtain robustness. The total proposed control system has the following form:

$$
\mathrm{u}=\mathrm{u}_{\mathrm{i}}-\mathrm{u}_{\mathrm{RCMAC}}-\mathrm{u}_{\mathrm{CC}}
$$

The control diagram and the structure of the RCMAC are shown in Figures 5 and 6 respectively. The RCMAC aims to learn the uncertainties, $\operatorname{UD}(\underline{x})$, which always exist in practical applications, in order to minimize the errors of the system. To reduce the number of the variables in the computation of the control system, error, derivation of error, and integral of error are integrated to form the error sliding surface, $\mathrm{S}$ which is minimized by the RCMAC during learning [30]. According to the learning capability of the RCMAC, the error sliding surface will converge to zero at the appropriately selected learning rate. However, due to the uncertainties' effects, the error sliding surfaces often oscillate around zero point and easily diverge in the presence of disturbances or noise. Therefore, a compensator controller was combined with the RCMAC to guarantee the robustness of the system during operation [28, 30]. This RCMAC (Figure 6) includes input space $\mathbf{S}$, association memory space $\mathbf{A}$, receptive field space $\mathbf{R}$, weight memory space $\mathbf{W}$, and output spaces $\mathbf{O}$. The function value of each space in the RCMAC is represented as [30]:

$$
\begin{gathered}
\mathrm{s}_{\text {rik }}(\mathrm{t})=\mathrm{s}_{\mathrm{i}}(\mathrm{t})+\mathrm{w}_{\text {rik }} \mu_{\mathrm{ik}}(\mathrm{t}-1) \\
\mu_{\mathrm{ik}}\left(\mathrm{s}_{\text {rik }}\right)=\exp \left[-\frac{\left(\mathrm{s}_{\mathrm{ri}}-\mathrm{m}_{\mathrm{ik}}\right)^{2}}{\sigma_{\mathrm{ik}}^{2}}\right] \\
\mathrm{b}_{\mathrm{ik}}=\prod_{\mathrm{i}=1}^{\mathrm{n}} \mu_{\mathrm{ik}}\left(\mathrm{s}_{\mathrm{rik}}\right) \\
\mathrm{O}_{\mathrm{j}}=\sum_{\mathrm{j}=1}^{\mathrm{nj}} \sum_{\mathrm{k}=1}^{\mathrm{nk}} \mathrm{w}_{\mathrm{jk}} \prod_{\mathrm{i}=1}^{\mathrm{n}} \mu_{\mathrm{ik}}\left(\mathrm{s}_{\mathrm{rik}}\right)
\end{gathered}
$$

The parameters of the controller are adjusted by the RCMAC's learning to achieve good performance in the presence of the lumped uncertainties $\mathrm{UD}(\underline{\mathrm{x}})$.

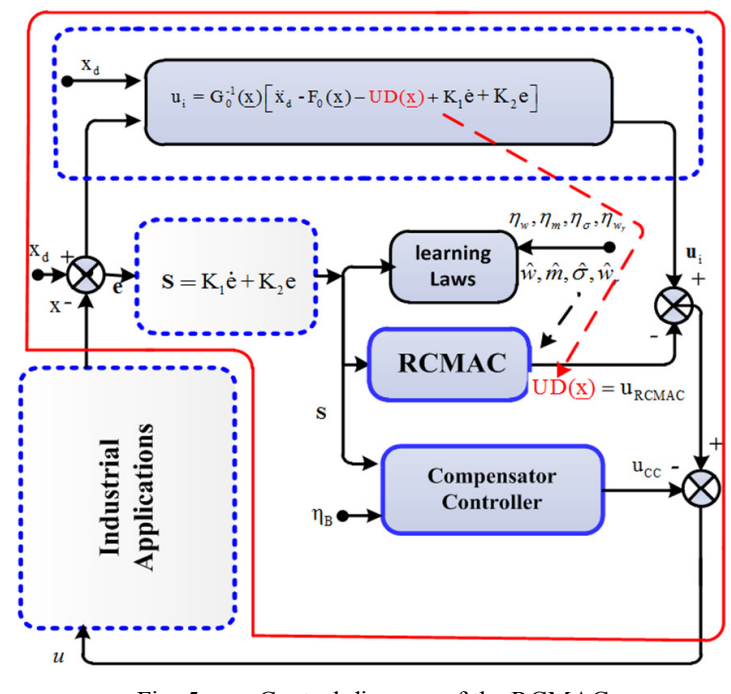

Fig. 5. Control diagram of the RCMAC
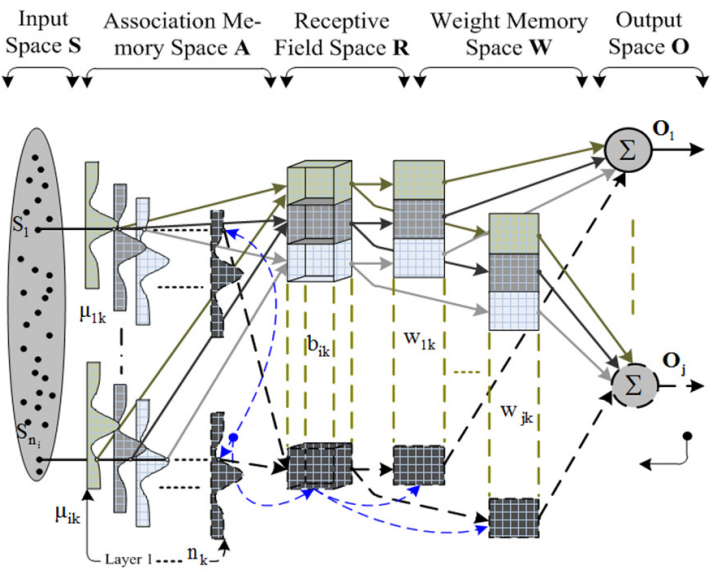

Fig. 6. Structure of the RCMAC

In this paper, $\mathrm{s}^{\mathrm{T}} \dot{\mathrm{S}}$ is selected as an error function and the back-propagation algorithm is utilized to adjust the parameters of the controller as follows:

$$
\begin{aligned}
& \mathrm{S}^{\mathrm{T}} \dot{\mathrm{S}}=-\mathrm{S}^{\mathrm{T}} \mathbf{F}_{0}(\underline{\mathbf{x}})-\mathrm{S}^{\mathrm{T}} \mathbf{G}_{\mathbf{0}}(\underline{\mathrm{x}})\left(\mathbf{u}_{\mathrm{ISM}}-\mathbf{u}_{\mathrm{RCMAC}}+\mathbf{u}_{\mathrm{CC}}\right) \\
&+\mathrm{S}^{\mathrm{T}}\left(\ddot{\mathbf{x}}_{\mathrm{d}}-\mathrm{UD}(\underline{\mathrm{x}})+\mathrm{K}_{1} \dot{\mathrm{e}}+\mathrm{K}_{2} \mathrm{e}\right) \\
& \Delta \mathrm{w}_{\mathrm{kj}}=-\eta_{\mathrm{w}} \frac{\partial \mathrm{S}^{\mathrm{T}} \dot{\mathrm{S}}}{\partial \mathrm{w}_{\mathrm{kj}}}=-\eta_{\mathrm{w}} \frac{\partial \mathrm{S}^{\mathrm{T}} \dot{\mathrm{S}}}{\partial \mathbf{u}_{\mathrm{RCMAC}}} \frac{\partial \mathbf{u}_{\mathrm{RCMAC}}}{\partial \mathrm{w}_{\mathrm{kj}}} \\
&= \eta_{\mathrm{w}} \mathrm{S}^{\mathrm{T}} \mathbf{G}_{0}(\underline{\mathrm{x}})\left(\prod_{\mathrm{i}=1}^{\mathrm{n}_{\mathrm{i}}} \mu_{\mathrm{ik}}\left(\mathrm{S}_{\mathrm{ri}}\right)\right) \\
& \Delta \mathrm{m}_{\mathrm{ik}}=-\eta_{\mathrm{m}} \frac{\partial \mathrm{S}^{\mathrm{T}} \dot{\mathrm{S}}}{\partial \mathrm{m}_{\mathrm{ik}}}=-\eta_{\mathrm{m}} \frac{\partial \mathrm{S}^{\mathrm{T}} \dot{\mathrm{S}}}{\partial \mathbf{u}_{\mathrm{RCMAC}}} \frac{\partial \mathbf{u}_{\mathrm{RCMAC}}}{\partial \mu_{\mathrm{ik}}} \frac{\partial \mu_{\mathrm{ik}}}{\partial \mathrm{m}_{\mathrm{ik}}} \\
&=\eta_{\mathrm{m}} \mathrm{S}^{\mathrm{T}} \mathbf{G}_{0}(\underline{\mathrm{x}}) \mathrm{w}_{\mathrm{kj}} 2 \frac{\left(\mathrm{S}_{\mathrm{ri}}-\mathrm{m}_{\mathrm{ik}}\right)}{\sigma_{\mathrm{ik}}^{2}}
\end{aligned}
$$




$$
\begin{aligned}
\Delta \sigma_{\mathrm{ik}}=-\eta_{\sigma} \frac{\partial \mathrm{S}^{\mathrm{T}} \dot{\mathrm{S}}}{\partial \sigma_{\mathrm{ik}}}= & -\eta_{\sigma} \frac{\partial \mathrm{S}^{\mathrm{T}} \dot{\mathrm{S}}}{\partial \mathbf{u}_{\mathrm{RCMAC}}} \frac{\partial \mathbf{u}_{\mathrm{RCMAC}}}{\partial \mu_{\mathrm{ik}}} \frac{\partial \mu_{\mathrm{ik}}}{\partial \sigma_{\mathrm{ik}}} \\
& =\eta_{\sigma} \mathrm{S}^{\mathrm{T}} \mathbf{G}_{\mathbf{0}}(\underline{\mathrm{x}}) \mathrm{w}_{\mathrm{kj}} 2 \frac{\left(\mathrm{S}_{\mathrm{ri}}-\mathrm{m}_{\mathrm{ik}}\right)^{2}}{\sigma_{\mathrm{ik}}^{3}} \\
\Delta \mathrm{w}_{\mathrm{rik}}=-\eta_{\mathrm{w}_{\mathrm{rik}}} \frac{\partial \mathrm{S}^{\mathrm{T}} \dot{\mathrm{S}}}{\partial \mathrm{w}_{\mathrm{rik}}} & =-\eta_{\mathrm{w}_{\mathrm{rk}}} \frac{\partial \mathrm{S}^{\mathrm{T}} \dot{\mathrm{S}}}{\partial \mathbf{u}_{\mathrm{RCMAC}}} \frac{\partial \mathbf{u}_{\mathrm{RCMAC}} \frac{\partial \mu_{\mathrm{ik}}}{\partial \boldsymbol{S}_{\mathrm{ik}}} \frac{\partial \mathrm{S}_{\mathrm{ri}}}{\partial \mathrm{ri}}}{\partial \mathrm{w}_{\mathrm{rik}}} \\
& =\eta_{\mathrm{w}_{\mathrm{rik}}} \mathrm{S}^{\mathrm{T}} \mathbf{G}_{\mathbf{0}}(\underline{\mathrm{x}}) \mathrm{w}_{\mathrm{kj}} 2 \frac{\left(\mathrm{S}_{\mathrm{ri}}-\mathrm{m}_{\mathrm{ik}}\right)}{\sigma_{\mathrm{ik}}^{2}} \mu_{\mathrm{i}(\mathrm{k}-1)}
\end{aligned}
$$

To maintain the robustness of the control system as the error function is tending to zero, a sliding mode control-based compensator controller can be designed as:

$$
\mathrm{u}_{\mathrm{CC}}=\mathrm{G}_{0}^{-1}(\underline{\mathrm{x}}) \hat{\mathrm{B}} \tanh (\mathrm{S})
$$

where $\mathrm{B}$ is the error boundary and $\hat{\mathrm{B}}$ is an estimation of B. In practical industrial applications, the error boundary cannot be exactly measured. Moreover, selecting the boundary error is a trade-off between the output chattering phenomenon and the stability of the control system. Consequently, the error boundary is estimated in this study as $[28,30]$ :

$$
\dot{\hat{\mathrm{B}}}=\eta_{\mathrm{B}}\|\mathrm{S}\|
$$

With the estimating rule given in (15), the stability of the system is guaranteed in the sense of Lyapunov-like Lemma [31].

\section{EXPERIMENTAL RESULTS}

\section{A. Water Level Stability Control System}

The water level control system is represented in Figure 7. The system includes a pump powered by a DeviceNet Network-controlled inverter. The water level in the tank is monitored by a Level Transmitter (LT). The LT's signal is connected to the inverter. All processes are performed by the control stations via the DeviceNet network. Data in the control stations are monitored by computers and a Human Machine Interface (HMI) via an Ethernet network. The initial parameters of the RCMAC of the control system are:

$$
\begin{aligned}
& \eta_{\mathrm{w}}=\eta_{\mathrm{m}}=\eta_{\sigma}=\eta_{\mathrm{wr}}=\eta_{\mathrm{B}}=0.001, \mathrm{n}_{\mathrm{k}}=7 \\
& \mathrm{~K}_{1}=0.035, \mathrm{~K}_{2}=0.054
\end{aligned}
$$

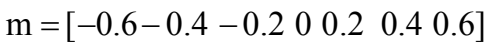

$$
\begin{aligned}
& \mathrm{W}=\left[\begin{array}{lllllll}
-0.4 & -0.25 & -0.15 & 0 & 0.15 & 0.25 & 0.4
\end{array}\right] \\
& \sigma=\left[\begin{array}{lllllll}
0.3 & 0.3 & 0.3 & 0.3 & 0.3 & 0.3 & 0.3
\end{array}\right] \\
& \mathrm{W}_{\text {rik }}=\left[\begin{array}{llllll}
-0.4 & -0.25-0.15 & 0 & 0.15 & 0.25 & 0.4
\end{array}\right]
\end{aligned}
$$

The response of the water level in the tank is shown in Figure 8. The experimental result shows that the RCMACS can control the water level in the tank and achieve different desired set points. Besides, the redundant solution guarantees the continuous control and supervisory process in case the controllers get faults. In particular, during the operation, if the PS is in the program mode, fault or outage power, the SS will take over the control of the system and maintain the process continuously.

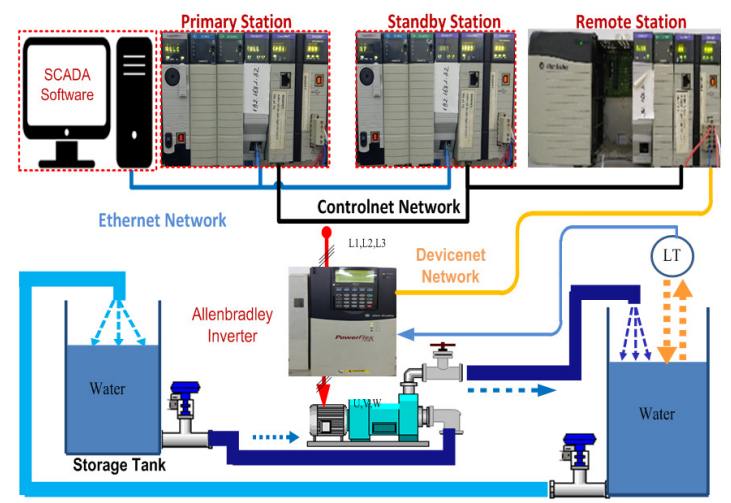

Fig. 7. Water level control system

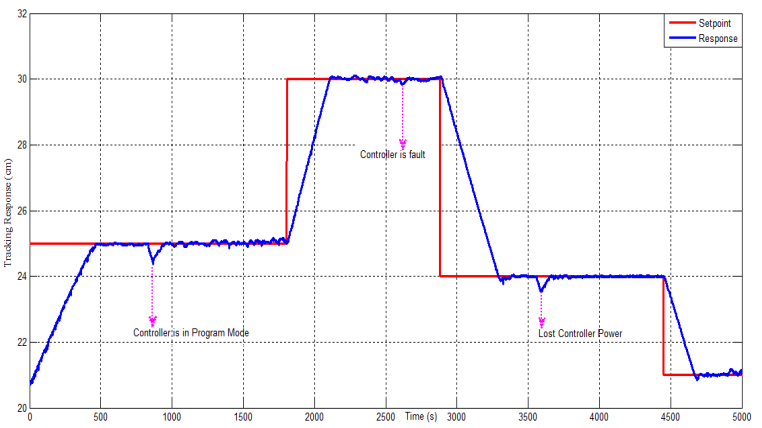

Fig. 8. The response of the water level in the tank

\section{B. Pressure Stability Control System}

The pressure stability control system is presented in Figure 9. The system includes a pressure pump powered by a DeviceNet Network-controlled inverter. The pressure in the tank is qualified by a pressure transmitter (PT). The PT's signal is connected to the inverter. All processes are performed by the control stations via the DeviceNet network.

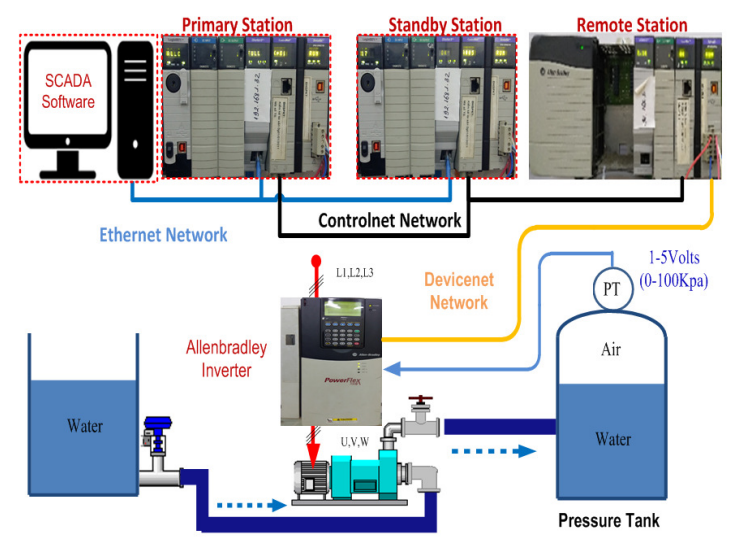

Fig. 9. Pressure stability control system 
The initial parameters of the RCMAC are the same with the case of water level control. The experimental results of the pressure stability control system are shown in Figure 10. The experimental results prove that the RCMACS can control the pressure in the tank and achieve the desired different references in reality. Along with achieving good responses, the redundant solution also guarantees the continuous control and supervisory process in case of fault in the controllers.

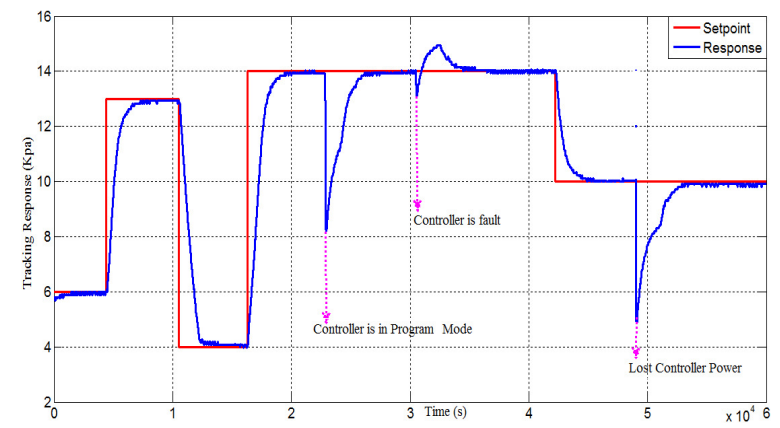

Fig. 10. The response of the pressure in the tank

\section{CONCLUSION AND FUTURE WORK}

Water level control system and pressure stability control system were controlled to achieve the desired trajectories by the redundant recurrent cerebellar model articulation control system. The parameters of the controller were learned and turned in real time, and the stability and robustness of the control system are guaranteed in the Lyapunov sense. The exchange data between the control stations and the field devices were transferred via the industrial DeviceNet Network. This solution not only reduces the effects of noise and signal attenuation during operation, but also increases the distance between the control stations and sensors and actuators. Furthermore, the redundant solution was proposed in this study to maintain continuously the control and supervisory process. Two control stations were used to operate concurrently. Whenever one station faults, the other will quickly take over control of the system. Therefore, the continuous operation of the control system is guaranteed.

The use of historical data records, however, is one of the most crucial tasks in practical industrial applications. This is useful for users in finding and troubleshooting faults during operation. Future research work will include the implementation of this task.

\section{REFERENCES}

[1] S. Muthulakshmi, R. Dhanasekaran, "Speed control of switched reluctance motor using soft computing technique for industrial applications", Journal of Scientific and Industrial Research, Vol. 75, No. 5, pp. $285-288,2016$

[2] A. Sniders, T. Komass, "Invariant method of load independent pressure control in steam boiler", Electrical, Control, and Communication Engineering, Vol. 1, No. 1, pp. 5-10, 2013

[3] A. Venuprasad, Y. S. Narayan, "Automatic monitoring and controlling of pressure using PLC and SCADA", International Journal of Innovative Research in Science, Engineering and Technology, Vol. 5, No. 7, pp. 2347-6710, 2016
[4] M. Ramzan, A. Maqsood, "Dynamic modeling and analysis of a highpressure regulator", Mathematical Problems in Engineering, Vol. 2016, Article ID 1307181, 2016

[5] A. Usha, H. P. M. Tech, K. V. L. Narayana, "Water tank level control system using self-adaptive fuzzy-PID control”, International Journal of Engineering Research \& Technology, Vol. 3, No. 6, pp. 1992-1997, 2014

[6] J. A. John, N. E. Jaffar, R. M. Francis, "Modelling and control of coupled tank liquid level system using backstepping method", International Journal of Engineering Research \& Technology, Vol. 4, No. 6, pp. 667-671, 2015

[7] Z. Ma, A. Juan, "Control of a pressure tank system using a decoupling control algorithm with a neural network adaptive scheme", IEE Proceedings-Control Theory and Applications, Vol. 150, No. 4, pp. 389400, 2003

[8] X. Fang, T. Shen, X. Wang, Z. Zhou, "Application and Research of Fuzzy PID in Tank Systems", Fourth International Conference on Natural Computation, Jinan, China, October 18-20, 2008

[9] H. F. Moghadam, N. Vasegh, "Robust PID stabilization of linear neutral time-delay systems", International Journal of Computers Communications \& Control, Vol. 9, No. 2, pp. 201-208, 2014

[10] J. Bai, "Development an adaptive incremental fuzzy PI controller for an HVAC system", International Journal of Computers Communications \& Control, Vol. 8, No. 5, pp. 654-661, 2013

[11] Z. Du, T. C. Lin, T. Zhao, "Fuzzy robust tracking control for uncertain nonlinear time-delay system", International Journal of Computers Communication \& Control, Vol. 10, No. 6, pp. 812-824, 2015

[12] F. Z. Kebbab, D. Jabri, D. E. C. Belkhiat, S. Belkhiat, "Frequency speed control of rotary travelling wave ultrasonic motor using fuzzy controller", Engineering, Technology \& Applied Science Research, Vol. 8, No. 4, pp. 3276-3281, 2018

[13] F. J. Lin, S. Y. Lee, P. H. Chou, "Intelligent integral backstepping sliding-mode control using the recurrent neural network for piezoflexural nanopositioning stage", Asian Journal of Control, Vol. 18, No. 2, pp. 456-472, 2016

[14] Z. B. Duranay, H. Guldemir, S. Tuncer, "Fuzzy sliding mode control of DC-DC boost converter", Engineering, Technology \& Applied Science Research, Vol. 8, No. 3, pp. 3054-3059, 2018

[15] M. Yildirim, C. Catalbas, A. Gluten, H. Kurum, "Computation of the speed of four in-wheel motors of an electric vehicle using a radial basis neural network", Engineering, Technology \& Applied Science Research, Vol. 6, No. 6, pp. 1288-1293, 2016

[16] C. H. Lin, "Nonlinear backstepping control design of LSM drive system using adaptive modified recurrent laguerre orthogonal polynomial neural network", International Journal of Control, Automation, and Systems, Vol. 15, No. 5, pp. 905-917, 2017

[17] C. H. Lu, "Design and application of stable predictive controller using recurrent wavelet neural networks", IEEE Transactions on Industrial Electronics, Vol. 56, No. 9, pp. 3733-3742, 2009

[18] F. J. Lin, S. Y. Chen, Y. C. Hung, "Field-programmable gate arraybased recurrent wavelet neural network control system for the linear ultrasonic motor", IET Electric Power Applications, Vol. 3, No. 4, pp. 289-312, 2009

[19] W. Yu, M. A. M. Armendariz, F. O. Rodriguez, "Stable adaptive compensation with fuzzy CMAC for an overhead crane", Information Sciences, Vol. 181, No. 21, pp. 4895-4907, 2011

[20] M. A. S. K. Khan, M. A. Rahman, "A novel neuro wavelet-based selftuned wavelet controller for IPM motor drives", IEEE Transactions on Industry Applications, Vol. 46, No. 3, pp. 1194-1203, 2010

[21] F. J. Lin, Y. C. Hung, S. Y. Chen, "FPGA-based intelligent dynamic sliding-mode control using recurrent wavelet neural network for a linear ultrasonic motor", IET Control Theory and Applications, Vol. 4, No. 9, pp. 1511-1532, 2010

[22] D. Shi, M. N. Nguyen, S. Zhou, G. Yin, "Fuzzy CMAC with incremental Bayesian ying-yang learning and dynamic rule construction", IEEE Transactions on Systems, Man and Cybernetics, Vol. 40, No. 2, pp. 548-552, 2010 
[23] C. M. Lin, H. Y. Li, "TSK fuzzy CMAC-based robust adaptive backstepping control for uncertain nonlinear systems", IEEE Transactions on Fuzzy Systems, Vol. 20, No. 6, pp. 1147-1154, 2012

[24] S. Y. Wang, C. L. Tseng, S. C. Chien, "Adaptive fuzzy cerebellar model articulation control for switched reluctance motor drive", IET Electric Power Applications, Vol. 6, No. 3, pp. 190-202, 2012

[25] T. Ngo, T. V. Phuong, "Robust adaptive self-organizing wavelet fuzzy CMAC tracking control for deicing robot manipulator", International Journal of Computers Communications \& Control, Vol. 10, No. 4, pp. $567-578,2015$

[26] V. P. Ta, X. K. Dang, T. Q. Ngo, "Adaptive Tracking Control Based on CMAC for Nonlinear Systems", International Conference on System Science and Engineering, Ho Chi Minh City, Vietnam, July 21-23, 2017

[27] V. P. Ta, X. K. Dang, "Improved Wavelet Cerebellar Model Articulation Controller for Precision Positioning of the Piezo-Driven Stage", IOP Conference Series: Materials Science and Engineering, Vol. 383, Article ID 012019, 2018

[28] T. Q. Ngo, M. K. Duong, D. C. Pham, D. N. Nguyen, "Adaptive wavelet CMAC tracking control for induction servomotor drive system", Journal of Electrical Engineering \& Technology, Vol. 14, No. 1, pp. 209-218, 2019

[29] C. M. Lin, T. L. Le, "WCMAC-based control system design for nonlinear systems using PSO", Journal of Intelligent \& Fuzzy Systems, Vol. 33, No. 2, pp. 807-818, 2017

[30] V. P. Ta, X. K. Dang, "An innovative recurrent cerebellar model articulation controller for piezo-driven micro-motion stage", International Journal of Innovative Computing, Information, and Control, Vol. 14, No. 4, pp. 1527-1535, 2018

[31] C. M. Lin, H. Y. Li, "A novel adaptive wavelet fuzzy cerebellar model articulation control system design for voice coil motors", IEEE Transactions on Industrial Electronics, Vol. 59, No. 4, pp. 2024-2033, 2012 